УАK 347.4/.5

ББК 67.404 .2

DOI 10.22394/1682-2358-2017-4-64-73

A.A. Khachatryan, postgraduate student of the Private Law Department, the Institute of Economics, Management and Law of the Russian State University for the Humanities, Head of the Legal Department of OOO "NTS"

A.Z. Arsenyan, Doctor of Sciences (Law), Professor, Director of the Department of Regional Policy, Russian Presidential Academy of National Economy and Public Administration

\section{PROBLEMS \\ OF LEGISLATIVE \\ PROVISION \\ OF SOME TYPES \\ OF LEASING}

A comparative analysis of types of leasing is drawn and their legislative recognition is grounded. The used asset lease is distinguished as a subtype of operating lease. The authorial amendments to the Federal Law No. 164-FZ "On Finance Lease" are proposed.

Key words and word-combinations: leasing, types of lease, operating lease, leaseback, sui generis, finance lease.
A.A. Хачатрян, аспирант кафедрь частного права Института экономики, упраљления и права Российского государственного гуманитарного университета, начальник юридического отдела OOO «HTC» (email: artak_www@mail.ru)

A.3. Арсенян, доктор юридиеских наук, профессор, директор Аепартамента региональной политики Российской академии народного хозяйства и государственной службы при Президенme РФ (email: arsenyan-az@ranepa.ru)

\section{ПРОБ $\Lambda$ МЫЫ ЗАКОНОААТЕАЬНОГО ОБЕСПЕЧЕНИЯ НЕКОТОРЫХ ВИАОВ АИЗИНГА}

\footnotetext{
Аннотация. Проводится сравнительный анализ видов лизинга, с обоснованием их законодательного закрепления. Выделяется подвид оперативного лизинга - лизинг подержанного имущества. Предлагаются авторские корректировки в Федеральный закон № 164-Ф3 «О финансовой аренде (лизинге)».

Ключевые слова и словосочетания: лизинг, виды лизинга, оперативный лизинг, возвратный лизинг, sui generis, договор финансовой аренды.

B зависимости от срока полезного использования объекта мизинга, экономической сущности Аоговора мизинга и ряда Аругих обстоятельств в митературе, посвященной Аанному виду преАпринимательской Аеятельности, разАичают следующие разновидности мизинга. Финансовый лизинг

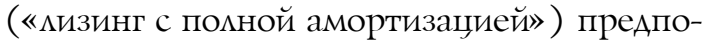
магает покупку имущества дия передачи в пользование на срок, сопоставимый со сро-
} 
ком амортизации мизингового имущества. Так, в США договор финансового мизинга заключается на срок не менее тридџати мет, хотя этот аспект относится не к мюбой разновидности цизинга, а только к имуществу с наиболее Аолгим амортизационным сроком, например к неАвижимости [1, с. 93] .

Предметом финансового мизинга обычно явцяется Аорогостоящее оборуАование с большим сроком физического износа. Как правило, по окончании Аоговора цизинга остаточная стоимость объекта мизинга близка к нулю, и объект может без дополнительной опиаты перейти в собственность мизингопомучателя. По сути финансовый мизинг явцяется одним из способов привлечения мизингополучателем целевого финансирования (в цемях приобретения объекта мизинга). Признаки финансового мизинга: участие третьей стороны - продавца (который знает, что приобретаемый у него товар предназначается именно Аля кизинга); приобретение товара кизингодателем именно Аля данной цели; передача товара мизингополучателю, который имеет право все претензии по качеству товара предъявцять непосредственно продавцу; невозможность Аосрочного расторжения Аоговора при отсутствии нарушений его усмовий оАной из сторон [2, с. 28, 41].

Срок договора оперативного лизинга («мизинга с неполной окупаемостью», «лизинга с неполной амортизацией», «сервисного мизинга»), в отличие от финансового мизинга, существенно меньше нормативного срока служббы объекта. Обычно предметом оперативного мизинга явцяются объекты краткосрочной необходимости (такой подход практикуется, например, в строительстве, сельском хозяйстве и т.А.), а также оборудование с высокими темпами морального старения [2, с. 30]. Например, компьютеры устаревают намного раньше физической амортизации, поэтому отрасли, связанные с использованием компьютеров и аналогичной оргтехникой, заинтересованы в оперативном мизинге [3, с. 86].

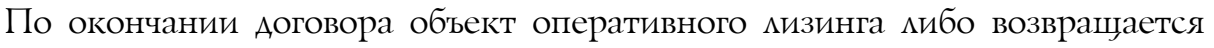

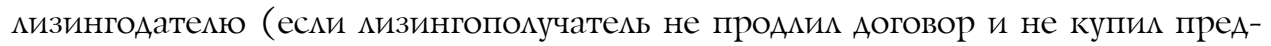
мет мизинга) и можкет быть передан в мизинг повторно, мибо (как исключе-

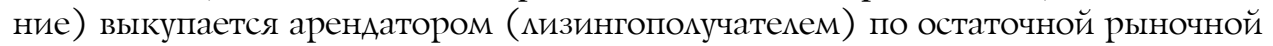
стоимости [4, с. 58-59].

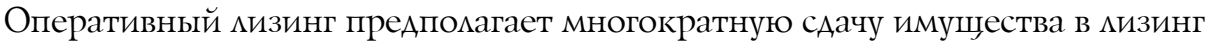
многим пользователям и высокие платежи по нему, что вполне объяснимо: Аоход Аизингодателя зависит от конъюнктуры рынка, гарантий окупаемости нет, а обязанности по техническому обслуживанию, ремонту, страхованию от риска случайной гибели, утраты, порчи и иного ввиАу краткосрочности мизинговых отношений с каждым отдельным мизингополучателем возмагаются, в отличие от финансового цизинга, на цизингодателя как собственника имущества.

Особый скучай представмяет собой бозбратный хизинг, при котором проАавец кизингового имущества одновременно явцяется цизингополучателем. Например, завод сам продает мизингодателю свое оборудование и сам же арендует его у него. По сути мизингодатель кредитует продавца (он же кизингополучатель) под залог этого самого (Аизингового) имущества [2, с. 37]. С 
экономической точки зрения возвратный мизинг преАставцяет собой креАито-

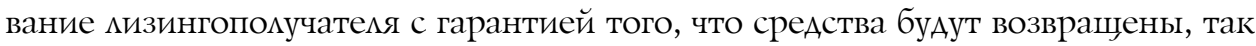

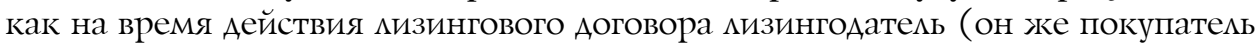
имущества) становится его собственником [5, с. 180] .

После выпиаты мизинговых платежей продавец- иизингполучатель может выкупить предметы мизинга по остаточной стоимости или получить бесплатно с учетом амортизации и уже выплаченных мизинговых платежей. ОАнако

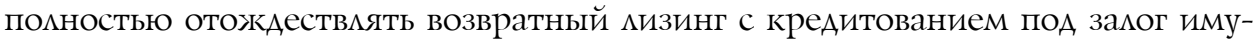
щества нельзя, так как сам залог не оформияется [4, с. 15]. Можно изменить это положение так, чтобы залог оформиялся, дия чего необходимы законодательные поправки.

Помимо получения кредита под залог производственных фондов, при возвратном мизинге налицо еще и выгода от получения дополнительного экономического эффекта в результате разцичий в налогообложении (имеются в виАу положенные при отношениях мизинга мьготы - ускоренная амортизация, искмючение мизинговых платежей из налогооблагаемой базы и Ар.).

Возвратный мизинг используется Аля преодоления неплатежей в случаях, если у мизингополучателя (он же продавец) нет оборотных средств. При возвратном мизинге имеется возможность более целесообразного использования мизингового имущества. Продажка имущества при этом осуществляется не по балансовой, а по рыночной стоимости.

Аизинг для физических лиц особенно интересен для предпринимателей без образования юридического мица (ПБОЮ $)$ ).

При чистом хизинге все расходы по обслуживанию имущества возмагаются

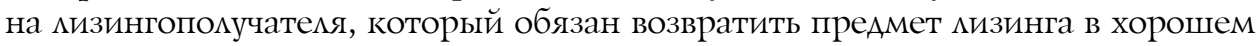
состоянии с учетом износа.

Полньй хизинг (цизинг с полным сервисом, цизинг в пакете) означает, что все расходы по обслужкиванию имущества межкат на мизингодателе [2, с. 30-35] . Очевидно, что чистый мизинг примерно совпадает с финансовым, а полный - с оперативным. Очевидно, что примерно так же мизинг подразделяется по степени окупаемости (полная или неполная - в зависимости от сроков, которые, в свою очередь, зависят от разновидности кизинга) [2, с. 40] .

Промежуточное положение межАу этими Авумя видами кизинга занимает частичньй хизинг, при котором на мизингодате я возмагается не полный объем обслуживания имущества, как при полном мизинге, а часть его.

Кроме того, размичают срочньий лизинг (одноразовая аренда); бозобновляемьй лизинг (его разновидность - ребольъерньий), преАполагающий продиение договора после окончания срока его действия, а также то, что объект по мере износа (ици по истечении очередного срока действия) и по жкеланию мизингополучателя может меняться на более совершенный. Разница состоит в том, что револьверный цизинг предполагает замену оборудования более совершенным по истечении очередного срока Аоговора, а возобновцяемый - по

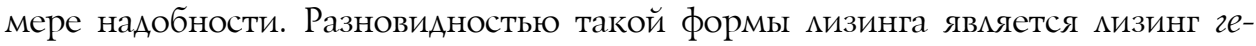
неральньй, когда под соглашением подразумевается возможность дополнить арендуемое оборудование без заключения новых контрактов [6, с. 32]. 
Иизинг подраздемяется также на прямой, когда мизингодателем выступает сам продавец (производитель) и договор мизинга носит характер двустороннего) и косъенньй (через посредника (в упрощенном порядке кизингодатель может быть и кредитором) [2, с. 35]. По объекту (типу имушества) бывает хизинг движимого имуцества (в первую очередь сюда относятся автомобили) и лизинг недвижимости. Еще одна разновидность - левередж-лизинг (от англ. «раздемьный»), когда объединяются несколько крупных организаций дия финансирования крупных мизинговых проектов [7, с. 62]. Часто мевередж-лизинг называют косвенным Аизингом [6, с. 31]. Групповой лизинг предполагает объединение группы участников Аля инвестирования средств в мизинговые сделки [4, с. 17].

Различают также международный и бнутренний мизинг, причем согласно российскому законодательству к первой категории относится и мизинг межАу Авумя российскими сторонами, если одна из них ведет дела и / или имеет совместный капитал с иностранным хозяйствующим субъектом (п. 1 ст. 7 Федерального закона № 164: «При осуществлении внутреннего мизинга Аизингодатель и кизингополучатель явмяются резидентами Российской Федерации. При осуществлении межкународного Аизинга Аизингодатель или мизингополучатель является нерезидентом Российской Федерации»).

Финансовый лизинг - самая распространенная разновидность мизинга. Нередко и законодатели, и авторы научных работ, посвяшенных кизинговым отношениям, рассматривают как мизинг только данную его разновидность. Об этом свидетельствует гл. 6 ГК РФ «Финансовая аренда ( иизинг)». 3Аесь неоАнократно подчеркивается признание кизингом только мизинга финансового. Статья 665 ГК РФ также гласит: «По договору финансовой аренды (Аоговору мизинга) арендодатель обязуется приобрести в собственность указанное аренАатором имушество у определенного им продавца и предоставить арендатору это имущество за плату во временное владение и пользование... Особенности договора финансовой аренды (Аоговора мизинга), закмючаемого государственным или мунищипальным учреждением, устанавливаются Федеральным законом от 29 октября 1998 года № 164-ФЗ...». В прочих статьях указанной

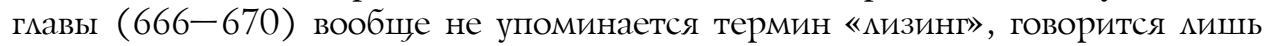
о «финансовой аренде», что также подтверждает признание мизингом только финансового мизинга.

В Федеральном законе № 164-ФЗ «О финансовой аренде (кизинге)» утверждается то же самое, хотя в его преамбуле отмечено: «Цемями настоящего Федерального закона явмяются развитие форм инвестиций в средства производства на основе финансовой аренды (лизинга)..., а в дальнейшем в тексте Закона упоминается только термин «мизинг», без повторения термина «финансовая аренда». При этом не предусматривается иного мизинга, кроме финансового, а в качестве видов (форм) мизинга выделяется мишь международный и внутренний (ст. 7: «1. Основными формами кизинга явцяются внутренний мизинг и межАународный мизинг). В связи с этим некоторые авторы высказывают мнение о том, что в России де-факто отсутствует единый закон о мизинге, а существует только Закон о финансовой аренде (точнее - о финансовом мизинге) как его разновидности [1, с. 132]. 
В конвенции УНИАРУА «О межАУнародном финансовом Аизинге» также прописано, что мизинг возможен только финансовый, а оперативный кизинг - это уже не кизинг, а аренда. В международных стандартах финансовой отчетности (Аалее - МСФО) термин «иизинг» не используется, поскольку есть финансовая аренда и оперативная (вместо «оперативный» используется термин «операционная аренда, «операционный мизинг») аренда. Следует, однако, отметить, что в МСФО финансовую аренду называют цизингом, а оперативную (операционную) - арендой, то есть опять проводится разАичие межАу полностью признанным (согласно российскому законодательству) финансовым мизингом, цизингом как таковым, и не совсем признанным кизингом оперативным.

Таким образом, российское законодательство, если не считать внутренний и межАународный Аизинг, признает только один виА Аизинговой Аеятельности - финансовый кизинг (финансовую аренду) как внутри страны, так и на международном уровне, что порождает ряд спорных вопросов. Особый интерес представляют проблемы мегализации двух видов цизинга - оперативного и возвратного, - основного объекта исследования данной статьи. Именно эти разновидности наиболее актуальны для малого и среднего преАпринимательства, поскольку субъекты подобного вида деятельности не всегда располагают необходимыми возможностями аля длительного («классического», финансового) мизинга, а также дмя инновационных видов экономики, так как высокотехнологичное оборудование устаревает, как правило, значительно раньше сроков его амортизаџии.

Важность дмя отечественной экономики инновационных методов малого и среднего предпринимательства сегодня никем не оспаривается. По разным данным, домя малого предпринимательства в России составцяет от 8 до 20\% ВВП, тогда как в странах ЕС этот показатель равен 70\%, в США - более 50\%.

Актуальность договоров оперативного, возвратного и им подобных разновидностей мизинга, впрочем, становится меньшей по мере сокращения нормативных сроков служжбы оборудования. В США, например, эти сроки сократились с 19 мет в 1940-х годах до 10 мет уже к 1972 г. Эти проџессы, помимо всего прочего, стимулировали мизинг как таковой $[8$, с. 22] .

Тем не менее оперативный мизинг остается важным и актуальным видом лизинга. Аело в том, что Аоговор оперативного мизинга заключается обычно на срок от двух до пяти мет, то есть на срок значительно меньший, чем Ааже указанные снизившиеся нормативные сроки амортизации. В странах ЕС, как и в России, на такой срок заключается $71 \%$ всех мизинговых договоров, а в России $-70,6 \%$ [9, с. 30], что само по себе говорит о важности пробцемы.

Сушествует и законодательная проблема. Вылеление и применение термина «оперативный (или операционный) кизинг» явмяется в российской юридической китературе спорным. По отечественному праву повторная сдача имущества в кизинг невозможна, так как все мьготы уже получены, поэтому сделка признается цизингом, только если осуществлена под конкретного заказчика, и при расторжении кизингового контракта приходится снова покупать вещь и сдавать в аренду (уже просто в аренду, не в мизинг даже как «разновидность аренды») мибо продавать [10] . 
Более того, в последние пятнадџать иет положение с правовым обеспечением оперативного мизинга ухудшилось: п. 3 ст. 7 Федерального закона № 164, предусматривавший возможность оперативного мизинга, был искмючен согласно Федеральному закону № 10-Ф3 от 29 января 2002 г. Именно поэтому оперативный мизинг в России заключается сегодня мибо в виде «просто» аренды, Аибо путем создания дополнительного юридического миџа, продавца оборудования. Непризнанный (или «полупризнанный») характер повторного (значит, и оперативного) мизинга в России порождает дополнительные налоговые риски.

МежАу тем оперативный цизинг актуален, например, когда мизингополучатель не хочет или не может выкупить предмет иизинга. Это важно Амя малого и среднего преАпринимательства с его ограниченными финансовыми возможностями: сегодня многие субъекты малого предпринимательства видят в кизинге (в первую очередь в краткосрочных его разновидностях) альтернативу банковскому кредитованию в силу ограниченности доступа к последнему. ОАнако пока на долю мизинга в России приходится всего 6\% финансирования малого предпринимательства; в странах ЕС этот показатель составляет $25 \%$.

Серьезной проблемой явмяется то, что мизинговые платежи необходимо вносить ежемесячно, а у малых предпринимателей доходы нередко носят сезонный характер [3, с. 102-105]. Так, договоры о международном мизинге предусматривают отсутствие у компаний стартового капитала при кизинге судов, самолетов, буровых вышек, включают пункты о растягивании и изменении сроков мизинговых платежей [11, с. 30]. Соответственно, следует предусмотреть и некий сходный порядок Амя предприятий малого бизнеса с преимушественным внесением мизинговых платежей в «доходные» сезоны.

В данной ситуации возникает проблема именно при краткосрочном, оперативном Аизинге, в чем и отличие от Аолгосрочного Аизинга судов, самолетов, буровых вышек дАя крупных компаний, поскольку краткосрочность приводит не только к повышению платежей, но и к необходимости для мизингодатемя требовать их вовремя, не относя на «доходные» сезоны, хотя срок договора от Авух до пяти мет подразумевает не менее двух "доходных» сезонов за время действия договора. К тому же в периоды кризисов (например, 2008 г.) оперативный мизинг в силу общего уменьшения финансовых ресурсов в бизнесе и экономике в целом делается важным не только для малого преАпринимательства $[1$, с. 88$]$, поэтому вопросы его законности требуют оперативного решения.

Отметим еще одну своеобразную форму оперативного мизинга, в митературе по мизинговым отношениям пока почти не упоминаемую, - Аизинг подер-

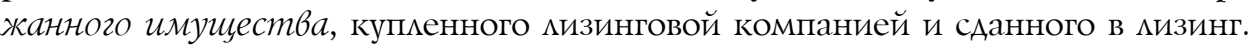
В условиях, когАа производственные мощности ряда преАприятий загружены далеко не полностью, такая форма мизинга весьма актуальна дмя более полной загрузки [6, с. 33], в том чисме, как представмяется, за счет не только деятельности специальных мизинговых компаний, но и путем образования дочерних

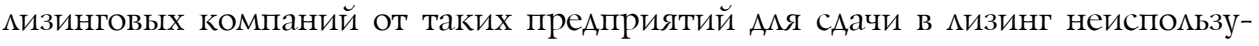
емого оборудования. 
Аанная разновидность мизинга нигде законодательно не признана, и, на наш взглял, требуется проработка возможности включения ее в Закон «О мизинге». Скорее всего, целесообразно отнести его к одной из перечисленных

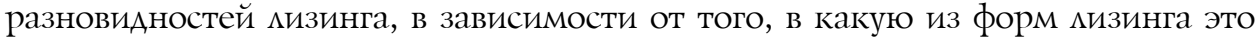
имущество будет сдано. В конце концов, нигде в Законе прямо не прописано,

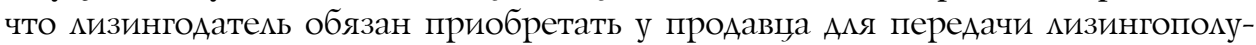
чателю только новое, а не подержанное имущество.

С Аругой стороны, нет и обратной информации. Так, ст. 2 Федерального закона № 164 гласит: «Аоговор мизинга - договор, в соответствии с которым арендодатель (далее - мизингодатель) обязуется приобрести в собственность

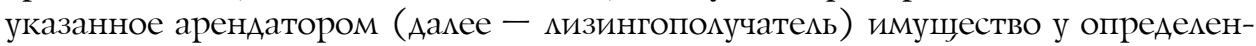

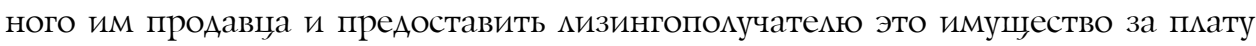
во временное владение и пользование. Аоговором мизинга может быть предусмотрено, что выбор продавца и приобретаемого имущества осуществляется $\Lambda и-$ зингодателем; мизинговая деятельность - вид инвестиционной деятельности по приобретению имущества и передаче его в мизинг». В п. 1 ст. 4 отмечается, что «Субъектами мизинга явмяются: мизингодатемь - физическое или юридическое миџо, которое за счет привлеченных и (или) собственных средств приобретает

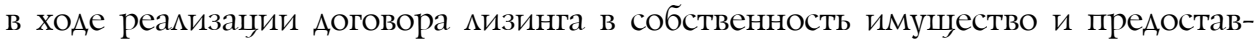

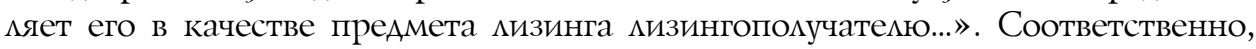
прямо насчет нового или подержканного имушества нигде ничего не сказано, поэтому необходимо, по нашему мнению, законодательно закрепить возмож-

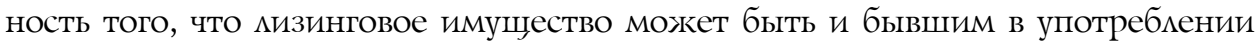
(подержанным) при условии сохранения надлежащего качества.

Использование бозбратного лизинга, в силу непризнанности или, вернее, «полупризнанности», порождает ряд проблем как с налоговыми органами (например, подозрение в намерении уйти от налогов, используя право на возврат НАС и иьготы по налогам на прибыль и имущество), так и вообще с преАставитемями вцасти и закона.

Высший Арбитражный СУА РФ (Аалее - ВАСРФ) рядом постановлений разъяснил, что сделки по возвратному мизингу законны, обоснованны и имеют разумные хозяйственные мотивы и цели Аля обеих сторон, а потому не направцены на «необоснованную налоговую экономию», однако многие хозяйствующие субъекты по-прежнему опасаются разбирательства в судах, следовательно, объемы возвратного мизинга снижаются (по крайней мере, снижались вплоть до 2007 г.) [3, с. 87-88]. Иными словами, вопрос с возвратным мизингом также необходимо решать на законодательном уровне.

Точнее, п. 1 ст. 4 Федерального закона № 164 в редакции Федерального закона № 10 от 29 января 2002 г. предусматривает, что «продавеџ можкет

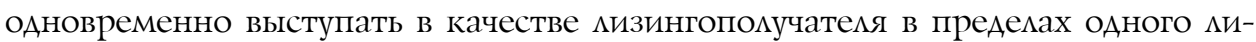
зингового правоотношения», чем и признается законодательно возможность возвратного мизинга, однако нигде в законодательстве не отмечено, что воз-

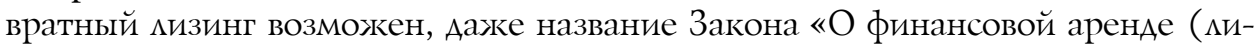
зинге)» по-прежкнему предполагает только финансовый цизинг. Аанная про-

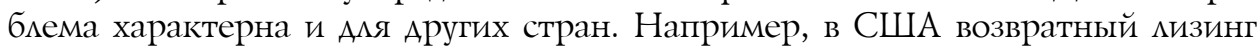
не имеет ряда налоговых и Аругих мьгот [8, с. 26]. 
О.Б. Волошина констатирует, что аренда подразделяется на краткосрочную (Ао одного года), среднесрочную (от года до трех) и Аолгосрочную (свыше трех мет). Что касается мизинга, то в первоначальной редакции Федерального закона № 164 (от 29 октября 1998 г.) тоже было записано нечто подобное, но такой подход, как полагает О.Б. Волошина, был правильным дмя 1990-х годов, когда нестабильность, в том числе и финансовая, вынуждала к краткосрочности также и лизинговых отношений. В редакции Федерального закона № 164 от 29 января 2002 г. это положкение исключено [12, с. 4-8].

Обратим внимание, что искмючение этого положения происходицо одновременно с искмючением из того же Закона нормы, подразумевающей возможность оперативного мизинга. С учетом уже упоминавшейся актуальности оперативного Аизинга как дмя малого и среАнего преАпринимательства, так и для инновационных видов бизнеса, это исключение, по нашему мнению, является как минимум преждевременным, и необходимо восстановление указанных норм в Федеральном законе № 164.

В ГК РФ возвратный и оперативный мизинг не может быть признан как кизинг, а в кучшем случае - как самостоятельный виА аренды согласно п. 1 гл. 34. В.В. Витрянский, указывая на ряд серьезных недостатков Федерального закона № 164 и приводя конкретные примеры юридической безграмотности составителей этого Закона, делает вывоА, что следует применять только те нормы Федерального закона № 164, которые не противоречат ГК РФ, иначе получится правовая неразбериха [13, с. 248-250] .

Кроме того, необходимо обратить внимание на институт повторного мизинга в скучае Аосрочного расторжения договора мизинга при нарушении обязательств одной из сторон (в частности, о нарушении обязательств мизингополучателем, поскольку пробцема повторного кизинга при досрочном расторжении договора актуальна дмя Аизингодателя).

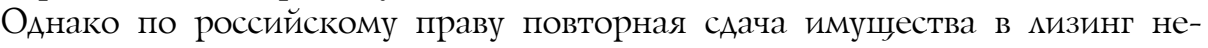
возможна, так как все мьготы (вкмючение кизинговых платежей в расходы, ускоренная амортизация объекта кизинга, снижение налога на имущество) уже получены, сделка признается кизингом, только если осуществлена поА конкретного заказчика, и при расторжении контракта приходится снова покупать вещь и сдавать в аренду мибо продавать [10] .

А.В. Кузнецов утвержАает, что ст. 9 Федерального закона № 164 предусматривала возможность повторного иизинга [14, с. 72-73], но в редакции от 29 января 2002 г. она была искмючена. Представляется целесообразным в свете изможенного институт повторного мизинга восстановить. И.С. Естигнеева и С.С. Юрьев отмечают, что была попытка ввести (правильнее восстановить) указанный институт, но из-за «сырого» характера предложенного законопроекта он быц отправлен на доработку [15, с. 41-42]. Очевидно, имелись в виду предложения от 2014 г. о том, что договор, заключенный $и$ зингодателем с новым кизингополучателем после расторжения предыдущего договора мизинга, должен считаться договором мизинга, а не аренды.

Это тем более обоснованно, поскольку мировой опыт свидетельствует об изменении отношения к повторному мизингу: если, в Конвенции УНИАРУА 


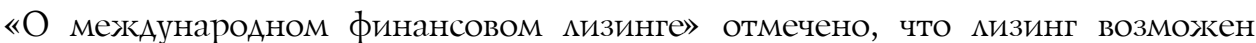

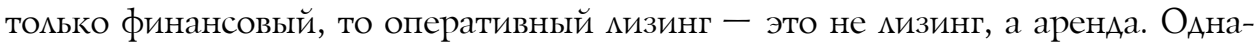
ко следует помнить, что 23 декабря 2010 г. Россия присоединилась к Кейптаунской конвенџии 2001 г. (ФеАеральный закон № 361-Ф3 «О присоеАинении Российской Федерации к МежАународной конвенџии о межАународных гарантиях в отношении подвижного оборудования») с 1 сентября 2011 г. Кейптаунская конвенџия 2001 г., в отличие от Конвенции УНИАРУА 1988 г., предусматривает повторный мизинг [15, с. 44] .

Таким образом, приходим к выводу, что необходимо выработать ряд рекомендаций относительно совершенствования правового регулирования кизинговых отношений. С учетом стоящих переА экономикой страны проблем актуален вопрос мегализации двух видов мизинга - оперативного и возвратного. В связи с этим следует восстановить возможность оперативного Аизинга, упраздненную в Федеральном законе № 164 в редакции от 29 января 2002 г. Искцючение этой нормы было явно преждевременным и не соответствовало развитию мизинга в современной экономике России.

Необходимо такжке более четко прописать возможноость возвратного Аизинга, во всяком случае ввести в законодательство этот термин, поскольку, пока этого не сделано, ни ввод в Федеральный закон № 164 пункта о возможности продавца имущества быть одновременно цизингополучателем, ни Аостаточно ясные и однозначные разъяснения ВАС РФ Аелу не очень помогают, и в обще-

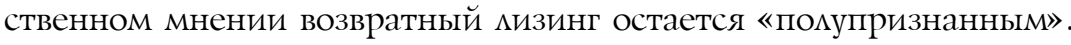

На случай досрочного расторжения договора мизинга при нарушении обя-

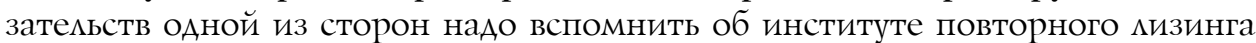

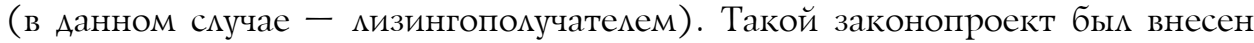
в Государственную Ауму РФ, но направлен на доработку ввиду «сырого» характера. Не вполне понятно, в какой форме этот законопроект, если он будет принят, получит право на существование. На наш взгляА, он Аолжен войти в Закон «О мизинге».

В настоящее время постепенно распространяется своеобразная форма оперативного мизинга - лизинг подержанного имущестьа, купленного мизин-

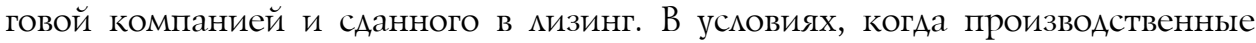
мощности ряда преАприятий загружены далеко не полностью, такая форма мизинга весьма актуальна дия более полной загрузки, но она пока нигде законодательно не признана, и на нее тоже необходимо обратить внимание, при этом целесообразно отнести его к одной из перечисленных разновидностей цизинга. При этом, однако, поскольку Федеральном законе № 164 отмечено, не Аолжно $и$ мизинговое имущество быть новым или может быть подержан-

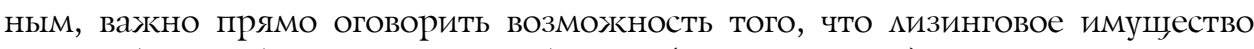
можкет быть и бывшим в употреблении (подержканным) при условии сохранения надмежащего качества.

Немаловажна и корректировка самого названия Федерального закона № 164-Ф3 «О финансовой аренде (мизинге)», которая, как уже подчеркивалось, отражает законодательное признание только одного вида цизинга. Некоторые авторы высказывают мнение о том, что в России де-факто от-

72 Bulletin of the Volga Region Institute of Administration • 2017. Vol. 17. № 4 
сутствует единый закон о мизинге, а существует только закон о финансовой аренде.

Тем не менее независимо от того, считать $и$ договор мизинга разновидностью договора аренды, как в основном принято в современной отечественной науке, или договором sui generis, как полагает автор, название Закона не отражает его сущности как закона о мизинге или одной из его разновидностей. На наш взглял, смедует это исправить и именовать данный Закон Федеральным законом «О мизинге».

\section{Библиографический список}

1. Горшков Р.К., Дикарёва В.А. Лизинг: проблемы и перспективы развития в России. М., 2012.

2. Антошина О.А. Лизинг. М., 2011.

3. Попов А.В., Попов Н.В., Желтов В.А. Правовое обеспечение лизинговых операций (инвестиции, проблемы, перспективы развития): учебное пособие. М., 2016.

4. Тилов А.А. Основы лизинга: учебное пособие. М., 2016.

5. Жамен С., Лакур Л. Торговое право. М., 1993.

6. Кузьмина Е.В., Морозова Н.В. Лизинг морских и речных судов в Российской Федерации: современный этап развития, особенности отражения в учете. СПб., 2016.

7. Газман В.Д. Финансовый лизинг и факторинг. М., 2008.

8. Алексеев C.B. Лизинг в Соединенных Штатах Америки и Российской Федерации: сравнительно-правовое исследование: дис. ... канд. юрид. наук. М., 2005.

9. Костина А.А. Лизинг для малого бизнеса: политэкономический и институциональный аспект. Ярославль, 2016.

10. Афанасьева М.B. Проблемы и перспективы развития финансовой аренды (лизинга) в современной России // Молодой ученый. 2008. № 1.

11. Павлодский E.A. Договоры организаций и граждан с банками. М., 2000.

12. Волошина О.Б., Федотов Н.Г. Лизинговые операции: учебное пособие. Пенза, 2012.

13. Витрянский В.В. Договор аренды и его виды: прокат, фрахтование на время, аренда зданий, сооружений и предприятий, лизинг. М., 1999.

14. Кузнецов Д.В. Кредитно-лизинговые отношения: теория и практика реализации. Владимир, 2014.

15. Евстигнеева И.С., Юрьев С.С. Современное правовое регулирование авиационного лизинга в Российской Федерации. М., 2014. 